\title{
Le récit d'enfance et ses modèles, Actes publiés sous la direction de Anne Chevalier et Carole Dornier, Colloque de Cerisy-la-Salle
}

\section{Gabriella Bosco}

\author{
(2) OpenEdition \\ Journals \\ Edizione digitale \\ URL: https://journals.openedition.org/studifrancesi/40048 \\ DOI: $10.4000 /$ studifrancesi. 40048 \\ ISSN: 2421-5856 \\ Editore \\ Rosenberg \& Sellier

\section{Edizione cartacea} \\ Data di pubblicazione: 1 décembre 2004 \\ Paginazione: 435-436 \\ ISSN: 0039-2944 \\ Notizia bibliografica digitale \\ Gabriella Bosco, «Le récit d"enfance et ses modèles, Actes publiés sous la direction de Anne Chevalier et \\ Carole Dornier, Colloque de Cerisy-la-Salle», Studi Francesi [Online], 143 (XLVIII | II) | 2004, online dal 30 \\ novembre 2015, consultato il 19 mai 2021. URL: http://journals.openedition.org/studifrancesi/40048 ; \\ DOI: https://doi.org/10.4000/studifrancesi.40048
}

Questo documento è stato generato automaticamente il 19 mai 2021.

\section{cc) (†) $\odot$}

Studi Francesi è distribuita con Licenza Creative Commons Attribuzione - Non commerciale - Non opere derivate 4.0 Internazionale. 


\title{
Le récit d'enfance et ses modèles, Actes publiés sous la direction de Anne Chevalier et Carole Dornier, Colloque de Cerisy-la-Salle
}

\author{
Gabriella Bosco
}

\section{NOTIZIA}

AA. VV., Le récit d'enfance et ses modèles, Actes publiés sous la direction de Anne Chevalier et Carole Dornier, Colloque de Cerisy-la-Salle (27 septembre-Ier octobre 2001), Caen, Presses Universitaires de Caen, 2003, pp. 318.

1 Il volume, esito del convegno sul racconto d'infanzia di Cerisy-la-Salle, si inscrive nell'ambito di un grande lavoro portato avanti dall'équipe di letteratura francese e comparata dell'università di Caen Basse-Normandie (Textes/Histoire/Langage) sul ruolo della scrittura nella costituzione della memoria.

2 L'orizzonte scelto è quello della Francia dal Medioevo ai giorni nostri, e include tanto i racconti autobiografici quanto quelli biografici, di finzione e non. Rispetto agli studi precedenti sul tema, si sono presi in considerazione anche i racconti d'infanzia che figurano in racconti di vita di più ampio respiro. $\mathrm{E}$ si è dato molto rilievo alla nozione di «modello», per una scrittura che -comportando la messa in scena di un'esperienza passata- implica necessariamente la strutturazione in racconto, elaborazione narrativa.

3 Le variazioni nel tempo del racconto d'infanzia, esplorate nelle varie sezioni del volume, sono legate - salta agli occhi - all'evoluzione della nozione di soggetto. Spartiacque, è la distinzione introdotta a questo proposito da PAUL RICOEUR, tra idem e ipse. Il racconto d'infanzia cambia concettualmente quando chi scrive ha per obiettivo, nel suo lavoro di indagine retrospettiva e soprattutto introspettiva, l'essere se stesso invece che lo stesso. Se chi ripercorre il proprio passato infantile vuole ritrovare non un 
adulto uguale al bambino che è stato, ma un adulto che è stato bambino, il percorso di scrittura inevitabilmente sarà diverso. Il mondo dell'infanzia, ricreato sulla pagina, non sarà più da vedere come anteriore a quello dello scrittore quale l'ex-bambino è poi diventato, ma posteriore, perché inevitabilmente filtrato dalla visione di un adulto che è scrittore.

4 Oggetto d'indagine sono però anche i racconti d'infanzia non «d'autore», ma di persone che abitualmente si occupano d'altro che di scrittura. L'analisi si fa allora, da letteraria, di carattere ontologico e sociologico. In altri termini, caratteristica costante dei colloqui di Cerisy, il tema è stato sviscerato in un'ottica che travalica le discipline, e che vuole coniugare diacronia e sincronia. Troppi gli interventi per citarli tutti: il volume, di ottimo livello, fornisce un quadro completo della questione, suggellato dall'Esquisse d'un bilan, straordinariamente efficace, di FRANCINE DUGAST PORTES. Molto interessante è anche l'apparato bibliografico, suddiviso in sezioni in base alle diverse discipline d'approccio. 